\title{
Integrating vector control across diseases
}

Nick Golding ${ }^{1 *}$, Anne L. Wilson², Catherine L. Moyes ${ }^{1}$, Jorge Cano ${ }^{3}$, David M. Pigott ${ }^{1}$, Raman Velayudhan ${ }^{4}$, Simon J. Brooker ${ }^{3}$, David L. Smith ${ }^{5,6,7}$, Simon I. Hay ${ }^{1,5,7}$ and Steve W. Lindsay ${ }^{2}$

\begin{abstract}
Background: Vector-borne diseases cause a significant proportion of the overall burden of disease across the globe, accounting for over $10 \%$ of the burden of infectious diseases. Despite the availability of effective interventions for many of these diseases, a lack of resources prevents their effective control. Many existing vector control interventions are known to be effective against multiple diseases, so combining vector control programmes to simultaneously tackle several diseases could offer more cost-effective and therefore sustainable disease reductions.
\end{abstract}

Discussion: The highly successful cross-disease integration of vaccine and mass drug administration programmes in low-resource settings acts a precedent for cross-disease vector control. Whilst deliberate implementation of vector control programmes across multiple diseases has yet to be trialled on a large scale, a number of examples of 'accidental' cross-disease vector control suggest the potential of such an approach. Combining contemporary high-resolution global maps of the major vector-borne pathogens enables us to quantify overlap in their distributions and to estimate the populations jointly at risk of multiple diseases. Such an analysis shows that over $80 \%$ of the global population live in regions of the world at risk from one vector-borne disease, and more than half the world's population live in areas where at least two different vector-borne diseases pose a threat to health. Combining information on co-endemicity with an assessment of the overlap of vector control methods effective against these diseases allows us to highlight opportunities for such integration.

Summary: Malaria, leishmaniasis, lymphatic filariasis, and dengue are prime candidates for combined vector control. All four of these diseases overlap considerably in their distributions and there is a growing body of evidence for the effectiveness of insecticide-treated nets, screens, and curtains for controlling all of their vectors. The real-world effectiveness of cross-disease vector control programmes can only be evaluated by large-scale trials, but there is clear evidence of the potential of such an approach to enable greater overall health benefit using the limited funds available.

Keywords: Disease mapping, Public health, Vector-borne disease, Vector control

\section{Background}

\section{The global impact of vector-borne diseases}

Vector-borne diseases impose a significant burden on human health and economic development $[1,2]$. Despite the vast scale of the problem, effective interventions are available to control many of these diseases and, therefore, reducing their burden is an achievable public health goal.

Nearly $82 \%$ of the global population live in areas at risk from one vector-borne disease with over half living in areas at risk of two or more of the major vector-borne

\footnotetext{
* Correspondence: nick.golding.research@gmail.com

${ }^{1}$ Wellcome Trust Centre for Human Genetics, University of Oxford, Oxford, OX3 7BN, UK

Full list of author information is available at the end of the article
}

diseases (see Additional file 1 for further details). The majority of this burden affects those living in low-income countries where resources for disease control are limited. Inhabitants of some parts of sub-Saharan Africa, south Asia, and the Americas are at risk from five or more major vector-borne diseases (Fig. 1). This overlap in the geographic distribution of the major vector-borne diseases suggests it is possible to leverage control resources to tackle these diseases simultaneously [3]. Herein, we identify the populations at risk of multiple major vector-borne diseases to highlight and quantify the opportunity for integrating vector control across these diseases.
() Biomed Central

(c) 2015 Golding et al. Open Access This article is distributed under the terms of the Creative Commons Attribution 4.0 International License (http://creativecommons.org/licenses/by/4.0/), which permits unrestricted use, distribution, and reproduction in any medium, provided you give appropriate credit to the original author(s) and the source, provide a link to the Creative Commons license, and indicate if changes were made. The Creative Commons Public Domain Dedication waiver (http://creativecommons.org/publicdomain/zero/1.0/) applies to the data made available in this article, unless otherwise stated. 


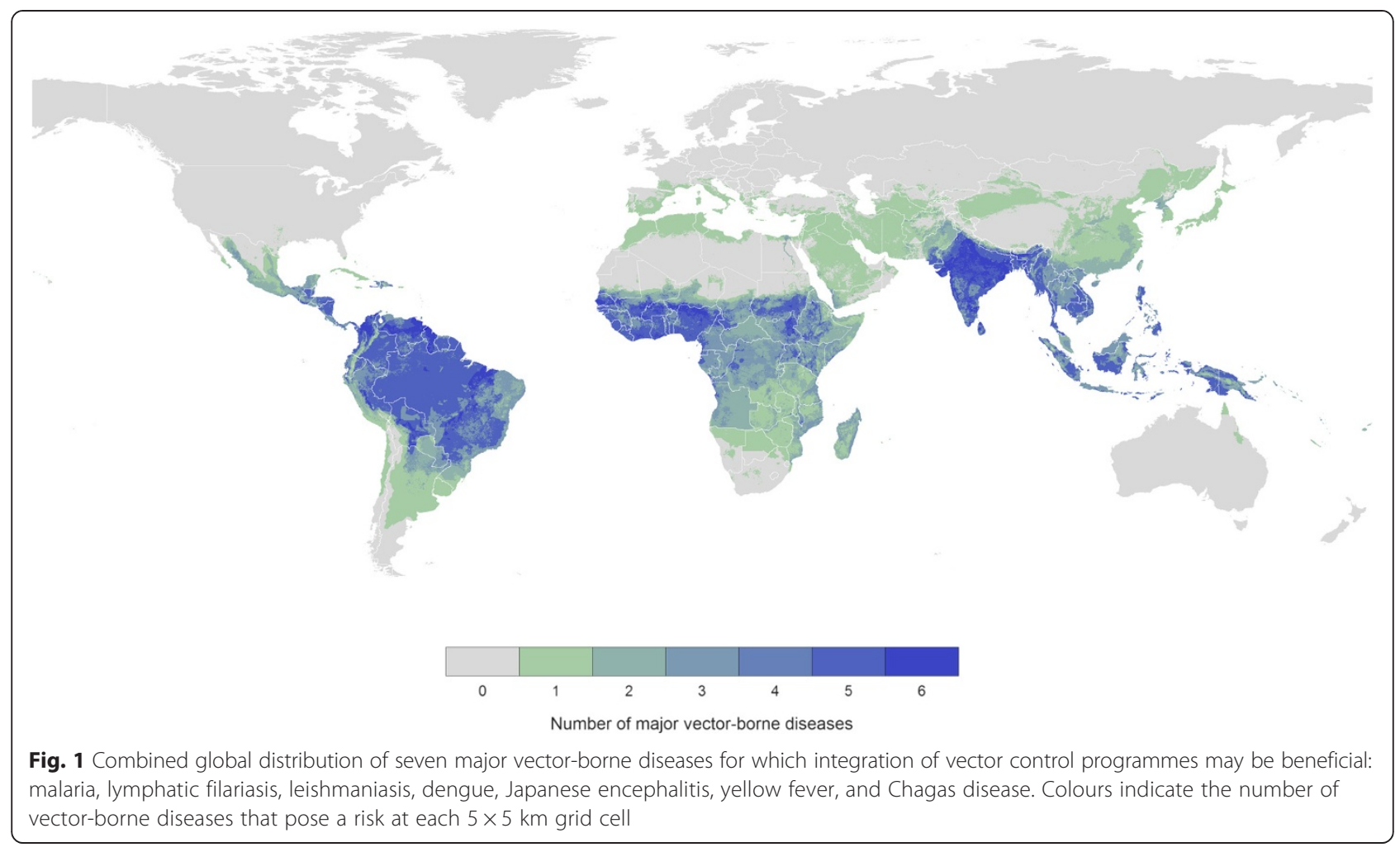

\section{Integrating vector control methods}

For many vector-borne diseases, vector control (targeting the arthropods that transmit the disease) is a highly effective means of reducing transmission. For some diseases, such as dengue and Chagas disease, vector control is the only approach currently available [4].

Large-scale vector control programmes have previously been responsible for the near-elimination of river blindness from much of West Africa and for shrinking the range of Chagas disease in South America [5, 6]. Vector control is currently carried out on a massive scale for the control of malaria, with long-lasting insecticidal nets (LLINs) and indoor residual spraying of insecticides reducing the burden of this disease in highly endemic parts of subSaharan Africa [7, 8].

Although progress has been made in reducing vectorborne disease endemicity, sustaining and advancing these gains requires intensification of control efforts [9]. Vectorborne disease control is hindered by dwindling financial resources as well as other challenges such as development of insecticide resistance [10]. Simultaneous deployment of multiple vector control methods, some of which are not based on insecticides, can reduce disease transmission to far lower levels than those achieved using a single intervention and help slow the development of insecticide resistance, thereby providing cost-effective and sustainable reductions in disease burden [11]. In areas with multiple vector species, insecticide resistance management programmes should be adopted as soon as resistance is detected in one vector species, although ideally such programmes should be introduced before resistance develops [12].

The simultaneous use of multiple methods is now the preferred vector control strategy and forms a cornerstone of integrated vector management - a best-practice framework for sustainable and cost effective vector control [13].

\section{Discussion}

Integrating control across diseases

In addition to integrating multiple vector control methods to target a single disease, simultaneously targeting multiple diseases using the same vector control programme infrastructure and possibly the same interventions has the potential for economies of scale and scope and even greater increases in cost-effectiveness. No large-scale vector control programmes have trialled multi-disease vector control, but several examples of 'accidental' control of vector-borne diseases suggest the potential of this approach.

Campaigns to reduce the incidence of malaria in India in the 1950s by indoor residual spraying of insecticides are credited with drastically reducing the burden from visceral leishmaniasis by killing its sand fly vectors as they rested inside homes [14]. Similarly, the mass rollout of LLINs in sub-Saharan Africa over the last decade is thought to have reduced the incidence of lymphatic filariasis, since 
these diseases share the same mosquito vector in rural areas [15].

Combining vector control activities across vector-borne diseases has the potential to be more cost-effective than parallel programmes. Cost savings would come both from reducing the direct costs of deploying interventions and from sharing the necessary support structures for these control programmes.

\section{Integrated vaccination and mass chemotherapy}

This integration of disease control programmes is not without precedent. For example, the initiation in 1974 of the Expanded Programme on Immunization was a ground-breaking move to combine the control programmes for several vaccine-preventable diseases into a single, largescale programme. By simultaneously deploying vaccines for a range of diseases, and combining the support structures required for large-scale immunization programmes, the Expanded Programme on Immunization was able to slash the costs of controlling each disease [16]. The subsequent development and rollout of polyvalent vaccines has further compounded these savings, enabling even cheaper and more effective disease control. Indeed, these vaccine distribution networks and other public health programmes have already been used as a cost-effective and equitable method for distributing LLINs $[17,18]$.

The successes of integrated vaccination programmes have recently been mirrored in the integration of mass chemotherapy control programmes for a number of neglected tropical diseases [19]. As with vector control, many of the drugs used in mass chemotherapy are efficacious against multiple diseases. The distribution mechanisms for these drugs are very similar and they can safely be administered together, meaning that cost savings can be made by administering multiple drugs in a single treatment round.

\section{Identifying opportunities for integration}

A crucial first step in assessing where and when an integrated approach to vector-borne disease control is likely to be effective is determining which interventions are effective against which diseases. Robust experimental studies of the effectiveness of vector control methods are unfortunately scarce for most diseases other than malaria [20, 21]. However, the limited studies available suggest that many vector control interventions are effective against several different vector-borne diseases [22].

For example, the most obvious candidates for synergy with malaria vector control methods are lymphatic filariasis (spread by the same mosquito vectors as malaria in rural Africa) and leishmaniasis (spread by the bite of sand flies). There is good evidence for the efficacy of insecticide-treated nets, screens, and curtains against both of these diseases, as several of the main vector species share the house-entering behaviour of the most important malaria vectors $[23,24]$. There is also limited evidence for the effectiveness of these methods at controlling the mosquito vectors of dengue and yellow fever, and of Japanese encephalitis [25-28]. Indoor residual spraying of insecticides is likely to be effective against leishmaniasis and lymphatic filariasis vectors $[29,30]$ and is known to be highly effective at controlling the Triatomine bug vectors of Chagas disease [31].

Larval source management is an effective (if not widely used) tool for the control of malaria [32] and can be combined with other vector control approaches for an additive reduction in malaria burden [33]. Similarly, larval control has been successfully combined with mass drug administration for the control of lymphatic filariasis in India [34]. Control of larval Aedes mosquitoes is a widely used intervention for tackling dengue [35] and was historically a key tool in the elimination of both dengue and yellow fever from Cuba and Panama [36].

Whilst insecticide treatment of nets, screens, and walls are implemented at the household level, larval source management must be targeted at the breeding sites of the specific vector species of interest, necessitating different procedures for different vectors. For example, application of larvicides is appropriate for controlling Anopheles [33], whereas polystyrene beads may be more effective for the urban Culex vectors of lymphatic filariasis [34] and the removal or larvicidal treatment of water containers is more useful for the Aedes vectors of dengue and yellow fever [35, 37]. Nevertheless, there are many situations where Anopheles and Culex mosquitoes share the same habitat [38, 39], and control operatives could reasonably be tasked to treat or remove the distinct larval habitats of several key species in a single programme, sharing many of the costs of control. The development of larval control products that are effective against multiple vectors could enhance these cost savings. Evaluating the practical feasibility and quantifying the cost-effectiveness of such crossdisease integration of larval source management should be considered in detail in future studies.

For many vector-borne diseases, improving the quality of housing can be an effective method of disease control $[40,41]$. Whilst house improvement can mean different things in different epidemiological situations (such as screening roof spaces for malaria control $[42,43]$ versus repairing plaster for Chagas disease [44, 45]), integrated programmes that carry out multiple improvements could be an effective approach for jointly controlling multiple diseases.

The likely impacts of applying control methods simultaneously against multiple vectors are a cause of debate amongst vector ecologists. However, a deliberate integration programme has so far never been applied operationally or evaluated in a research context. Therefore, evaluation of programmes targeting multiple vectors and diseases should 
be a priority for future research in order to determine the effectiveness, cost-effectiveness, and feasibility of this approach.

\section{Summary \\ Quantifying the opportunity for integration of vector control}

Quantifying the potential for cross-disease integration of vector control requires assessment of the overlap between vector-borne diseases, both in terms of populations affected and in the potential for integration of control. Using contemporary high-resolution risk maps we estimated the populations at risk from pairs of major vectorborne diseases. Figure 2 compares these figures with vector control methods that are likely to be effective against both diseases. Malaria, leishmaniasis, lymphatic filariasis, and dengue are prime candidates for joint control due to their significant public health impact, broad global distribution (populations at risk per pair of these diseases range between 1 and 2 billion people), and susceptibility to proven vector control methods. Of the 3.9 billion people living in areas at risk from at least two of the seven vector-borne diseases considered here, 3.5 billion (90\%) inhabit regions where two or more of these diseases are likely to be susceptible to the same intervention.

These global maps indicate where diseases are likely to overlap in their distributions, but diseases may not overlap at finer scales if their vectors have distinct environmental requirements. Large-scale cross-disease vector control programmes would need to be adapted to local-scale variation in order to best target the specific combination of diseases present in at-risk communities. Planning a large-scale programme of integrated vector control will therefore require more detailed knowledge of the spatial distribution of each disease, as well as their susceptibility to available vector control methods. As with any vector control programme, the interventions selected for control would need to be tailored to the local environment as well as to the vector species present. The operational effectiveness of multi-disease vector control programmes must then be evaluated in the field.

Whilst these hurdles mean that cross-disease integration of vector control may not be feasible in all of these areas, the scale of the potential public health gains is sufficiently large to warrant serious attention and future research. Given the limited funds available to control vector-borne diseases [10], successfully reducing the burden of these

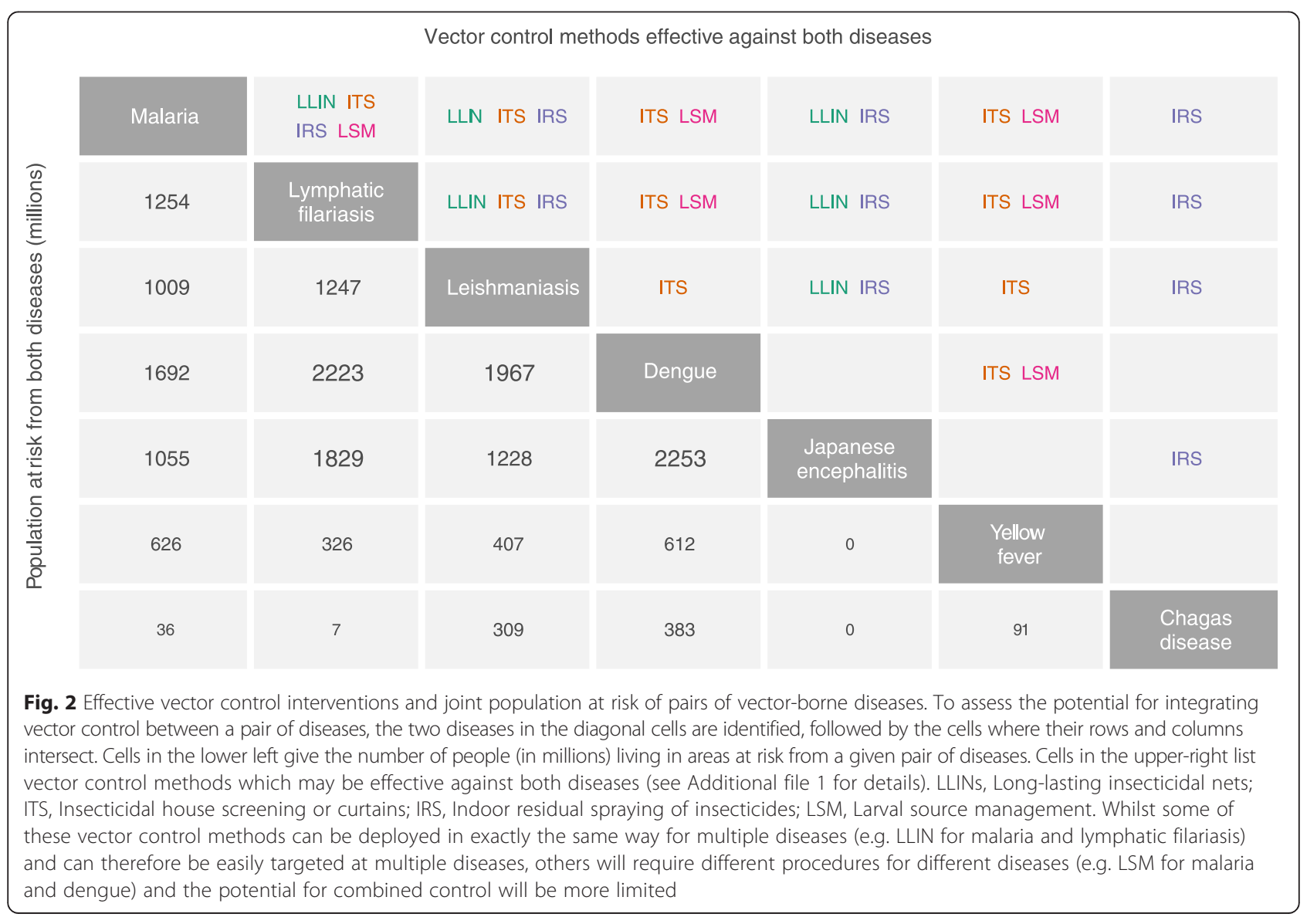


diseases requires new strategies to implement vector control cost-effectively. Leveraging vector control programmes in a single framework to attack multiple diseases promises a greater overall health benefit using the funds available. Mapping the global distribution of the populations suitable for cross-disease integration of vector control is the first step in quantifying the potential public health dividend.

\section{Additional file}

Additional file 1: Details of: selection of major vector-borne diseases and vector control interventions for evaluation, compilation of risk maps for these diseases, and calculation of joint population at risk estimates. (DOCX 2809 kb)

\section{Abbreviation}

LLINs: Long-lasting insecticidal nets.

\section{Competing interests}

The authors declare that they have no competing interests.

\section{Authors' contributions}

ALW and SWL carried out the literature review of intervention effectiveness. NG, JC, DMP, SIH, and SJB developed the risk maps. NG carried out the quantitative analysis and visualisation of results. CLM, DLS, and RV contributed examples and discussion of IVM. NG wrote the first draft of the manuscript and all authors contributed to writing the manuscript and read and approved the final manuscript.

\section{Acknowledgements}

Authors received funding from the Bill \& Melinda Gates Foundation (OPP1053338: NG, ALW, JC, RV, SJB, SIH, SWL; OPP1093011: CLM, SIH; OPP1033751: JC, SJB), GlaxoSmithKline (JC, SJB), the RAPIDD program of the Science \& Technology Directorate, Department of Homeland Security, and the Fogarty International Center, National Institutes of Health (DLS, SIH, SWL), a Sir Richard Southwood Graduate Scholarship (DMP), and Senior Research Fellowships from the Wellcome Trust (098045: SJB; 095066: SIH).

\section{Author details}

${ }^{1}$ Wellcome Trust Centre for Human Genetics, University of Oxford, Oxford, OX3 7BN, UK. ${ }^{2}$ School of Biological and Biomedical Sciences, Durham University, Durham DH1 3LE, UK. ${ }^{3}$ Department of Infectious and Tropical Diseases, London School of Hygiene \& Tropical Medicine, London WC1E 7HT, UK. ${ }^{4}$ Department of Control of Neglected Tropical Diseases, World Health Organization, 1211 Geneva, Switzerland. ${ }^{5}$ Institute of Health Metrics and Evaluation, University of Washington, Seattle, WA 98121, USA. ${ }^{6}$ Department of Zoology, University of Oxford, Oxford OX1 3PS, UK. ${ }^{7}$ Fogarty International Center, National Institutes of Health, Bethesda, MD 20892, USA.

Received: 20 March 2015 Accepted: 17 September 2015 Published online: 01 October 2015

\section{References}

1. Murray CJL, Vos T, Lozano R, Naghavi M, Flaxman AD, Michaud C, et al. Disability-adjusted life years (DALYs) for 291 diseases and injuries in 21 regions, 1990-2010: a systematic analysis for the Global Burden of Disease Study 2010. Lancet. 2012;380:2197-223.

2. Garg P, Nagpal J, Khairnar P, Seneviratne SL. Economic burden of dengue infections in India. Trans R Soc Trop Med Hyg. 2008;102:570-7.

3. Hotez P. Forgotten people. Forgotten diseases: the neglected tropical diseases and their impact on global health and development. Washington, DC: ASM Press; 2008.

4. Townson $H$, Nathan MB, Zaim M, Guillet P, Manga L, Bos R, et al. Policy and practice: exploiting the potential of vector control for disease prevention. Bull World Health Organ. 2005;83:942-7.
5. Basáñez M-G, Pion SDS, Churcher TS, Breitling LP, Little MP, Boussinesq M. River blindness: a success story under threat? PLoS Med. 2006;3:e371.

6. Schofield CJ, Jannin J, Salvatella R. The future of Chagas disease control. Trends Parasitol. 2006;22:583-8.

7. Gething PW, Battle KE, Bhatt S, Smith DL, Eisele TP, Cibulskis RE, et al. Declining malaria in Africa: improving the measurement of progress. Malar J. 2014;13:39.

8. World Health Organization. World Malaria Report 2014. Geneva: WHO; 2014.

9. Smith DLD, Cohen JJM, Moonen B, Tatem AJ, Sabot OJ, Ali A, et al. Solving the Sisyphean problem of malaria in Zanzibar. Science. 2011;332:1384-5.

10. Pigott DM, Atun R, Moyes CL, Hay SI, Gething PW. Funding for malaria control 2006-2010: a comprehensive global assessment. Malar J. 2012;11:246.

11. Beier JC, Keating J, Githure Jl, Macdonald MB, Impoinvil DE, Novak RJ. Integrated vector management for malaria control. Malar J. 2008;7:S4,

12. World Health Organization. Global Plan for insecticide resistance management in malaria vectors. Geneva: WHO; 2012.

13. World Health Organization. Handbook for integrated vector management. Geneva: WHO; 2012

14. Ostyn B, Vanlerberghe V, Picado A, Dinesh DS, Sundar S, Chappuis F, et al. Vector control by insecticide-treated nets in the fight against visceral leishmaniasis in the Indian subcontinent, what is the evidence? Trop Med Int Health. 2008;13:1073-85.

15. Van den Berg H, Kelly-Hope LA, Lindsay SW. Malaria and lymphatic filariasis: the case for integrated vector management. Lancet Infect Dis. 2013;13:89-94.

16. Levine OS, Bloom DE, Cherian T, de Quadros C, Sow S, Wecker J, et al. The future of immunisation policy, implementation, and financing. Lancet. 2011;378:439-48.

17. Grabowsky M, Nobiya T, Ahun M, Donna R, Lengor M, Zimmerman D, et al. Distributing insecticide-treated bednets during measles vaccination: A low-cost means of achieving high and equitable coverage. Bull World Health Organ. 2005;83:195-201.

18. Hanson K, Marchant T, Nathan R, Mponda H, Jones C, Bruce J, et al. Household ownership and use of insecticide treated nets among target groups after implementation of a national voucher programme in the United Republic of Tanzania: plausibility study using three annual cross sectional household surveys. BMJ. 2009;339:b2434.

19. Hotez P, Raff S, Fenwick A, Richards Jr F, Molyneux DH, Richards F. Recent progress in integrated neglected tropical disease control. Trends Parasitol. 2007;23:511-4

20. Picado A, Ostyn B, Rijal S, Sundar S, Singh SP, Chappuis F, et al. Long-lasting insecticidal nets to prevent visceral leishmaniasis in the Indian subcontinent; methodological lessons learned from a cluster randomised controlled trial. PLoS Negl Trop Dis. 2015;9:e0003597.

21. Wilson AL, Boelaert M, Kleinschmidt I, Pinder M, Scott TW, Tusting LS, et al. Evidence-based vector control? Improving the quality of vector control trials. Trends Parasitol. 2015;1-11.

22. Wilson A, Dhiman R, Kitron U. Benefit of insecticide-treated nets, curtains and screening on vector borne diseases, excluding malaria: a systematic review and meta-analysis. PLoS Negl Trop Dis. 2014;8:e3228.

23. Eigege A, Kal A, Miri E, Sallau A, Umaru J, Mafuyai H, et al. Long-lasting insecticidal nets are synergistic with mass drug administration for interruption of lymphatic filariasis transmission in Nigeria. PLoS Negl Trop Dis. 2013;7:e2508.

24. Ritmeijer K, Davies C, van Zorge R, Wang S-J, Schorscher J, Dongu'du SI, et al. Evaluation of a mass distribution programme for fine-mesh impregnated bednets against visceral leishmaniasis in eastern Sudan. Trop Med Int Health. 2007;12:404-14.

25. Kroeger A, Lenhart A, Ochoa M, Villegas E. Effective control of dengue vectors with curtains and water container covers treated with insecticide in Mexico and Venezuela: cluster randomised trials. Br Med J. 2006;332:1247.

26. Vanlerberghe $V$, Trongtokit $Y$, Jirarojwatana $S$, Jirarojwatana $R$, Lenhart $A$, Apiwathnasorn C, et al. Coverage-dependent effect of insecticide-treated curtains for dengue control in Thailand. Am J Trop Med Hyg. 2013;89:93-8

27. Dutta P, Khan SA, Khan AM, Borah J, Sarmah CK, Mahanta J. The effect of insecticide-treated mosquito nets (ITMNs) on Japanese encephalitis virus seroconversion in pigs and humans. Am J Trop Med Hyg. 2011:84:466-72

28. Che-Mendoza A, Guillermo-May G, Herrera-Bojorquez J, Barrera-Perez M, Dzul-Manzanilla F, Gutierrez-Castro C, et al. Long-lasting insecticide-treated house screens and targeted treatment of productive breeding-sites for dengue vector control in Acapulco, Mexico. Trans R Soc Trop Med Hyg. 2015;109:106-15. 
29. Reyburn H, Ashford R, Mohsen M, Hewitt S, Rowland M. A randomized controlled trial of insecticide-treated bednets and chaddars or top sheets, and residual spraying of interior rooms for the prevention of cutaneous leishmaniasis in Kabul, Afghanistan. Trans R Soc Trop Med Hyg. 2000;94:361-6.

30. Chang M, Ho B, Chan K. Efficacy of diethylcarbamazine and pirimiphos-methyl residual spraying in controlling brugian filariasis. Trop Med Parasitol. 1991;42:95-102.

31. Hashimoto K, Schofield CJ. Elimination of Rhodnius prolixus in Central America. Parasit Vectors. 2012;5:45.

32. Tusting $L$, Thwing J, Sinclair D, Fillinger U, Gimnig J, Bonner K, et al. Mosquito larval source management for controlling malaria. Cochrane Database Syst Rev. 2013;8:CD008923.

33. Fillinger $U$, Ndenga B, Githeko AK, Lindsay SW. Integrated malaria vector control with microbial larvicides and insecticide-treated nets in western Kenya: a controlled trial. Bull World Health Organ. 2009;87:655-65.

34. Sunish I, Rajendran R. Vector control complements mass drug administration against bancroftian filariasis in Tirukoilur. India Bull World Health Organ. 2007;85:138-45.

35. Erlanger TE, Keiser J, Utzinger J. Effect of dengue vector control interventions on entomological parameters in developing countries: a systematic review and meta-analysis. Med Vet Entomol. 2008;22:203-21.

36. Le Prince J, Orenstein A. Mosquito control in Panama: the eradication of malaria and yellow fever in Cuba and Panama. New York/London: Putnam; 1916.

37. Tun-Lin W, Lenhart A, Nam VS, Rebollar-Téllez E, Morrison XC, Barbazan P, et al. Reducing costs and operational constraints of dengue vector control by targeting productive breeding places: a multi-country non-inferiority cluster randomized trial. Trop Med Int Health. 2009;14:1143-53.

38. Fillinger U, Sonye G, Killeen GF, Knols BGJ, Becker N. The practical importance of permanent and semipermanent habitats for controlling aquatic stages of Anopheles gambiae sensu lato mosquitoes: operational observations from a rural town in western Kenya. Trop Med Int Health. 2004;9:1274-89.

39. Majambere S, Fillinger U, Sayer DR, Green C, Lindsay SW. Spatial distribution of mosquito larvae and the potential for targeted larval control in The Gambia. Am J Trop Med Hyg. 2008;79:19-27.

40. Wanzirah H, Tusting LS, Arinaitwe E, Katureebe A, Maxwell K, Rek J, et al. Mind the gap: house structure and the risk of malaria in Uganda. PLoS One. 2015;10:e0117396.

41. Dias JCP, Silveira AC, Schofield CJ. The impact of Chagas disease control in Latin America: a review. Mem Inst Oswaldo Cruz. 2002;97:603-12.

42. Kirby MJ, Ameh D, Bottomley C, Green C, Jawara M, Milligan PJ, et al. Effect of two different house screening interventions on exposure to malaria vectors and on anaemia in children in The Gambia: a randomised controlled trial. Lancet. 2009;374:998-1009

43. Lindsay SW, Emerson PM, Charlwood JD. Reducing malaria by mosquito-proofing houses. Trends Parasitol. 2002;18:510-4.

44. Monroy C, Bustamante DM, Pineda S, Rodas A, Castro X, Ayala V, et al. House improvements and community participation in the control of Triatoma dimidiata re-infestation in Jutiapa, Guatemala. Cad Saude Publica. 2009;25:S168-78

45. Rojas de Arias A, Ferro EA, Ferreira ME, Simancas LC. Chagas disease vector control through different intervention modalities in endemic localities of Paraguay. Bull World Health Organ. 1999;77:331-9.

\section{Submit your next manuscript to BioMed Central and take full advantage of:}

- Convenient online submission

- Thorough peer review

- No space constraints or color figure charges

- Immediate publication on acceptance

- Inclusion in PubMed, CAS, Scopus and Google Scholar

- Research which is freely available for redistribution 